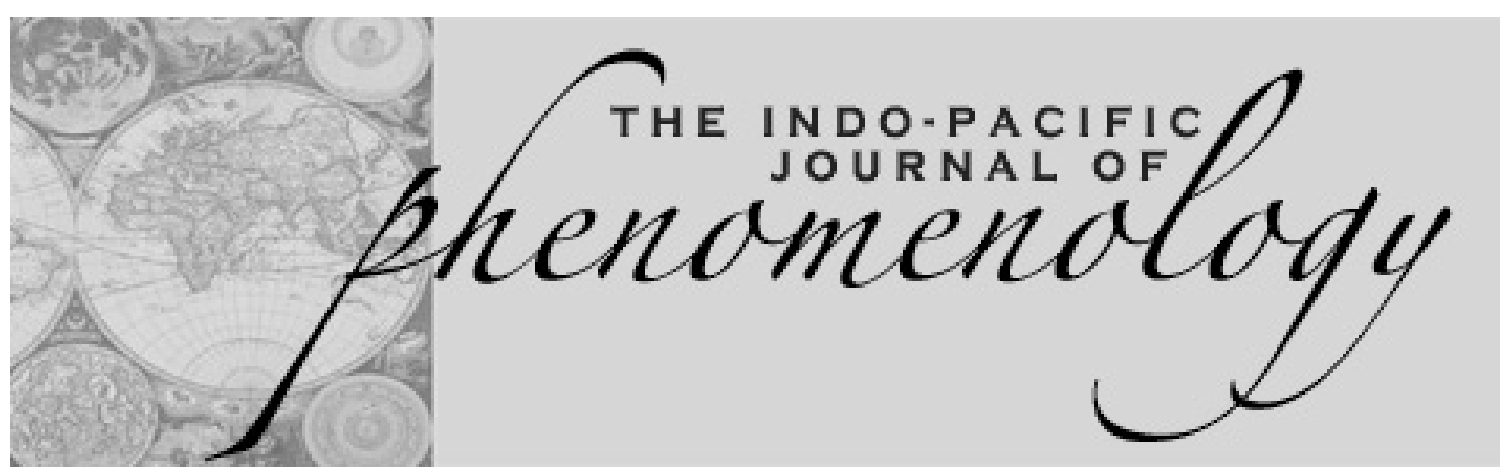

\title{
The Wound that Connects: A Consideration of "Narcissism" and the Creation of Soulful Space
}

by Dr Les Todres

This article develops an existential perspective on what has been called 'narcissism'. Using both the psychoanalytic tradition and the literary myth of Narcissus as 'touchstones', it unfolds a view of existential dilemmas and possibilities that are announced by this discourse. As such, it seeks to clarify the existential task of embodying human vulnerability - a journey that is potentially the source and depth of human compassion. With the help of the perspectives of A. H. Almaas and Eugene Gendlin, the phenomenon of 'soulful space' is named, and pursued in both logical and evocative ways. 'Soulful space' is articulated as an existential achievement and an alternative response to the call of Narcissus: an embodiment of both vulnerability and freedom; a freedom-wound that grounds interpersonal empathy and openness

\section{Introduction and Overview}

'There is a crack, a crack in everything, it's how the light gets in' (Cohen, 1992).

'We know separation so well because we've tasted the union. The reed flute makes music because it has already experienced changing mud and rain and light into sugarcane. Longing becomes more poignant if in the distance you can't tell whether your friend is going away or coming back. The pushing away pulls you in' (from a commentary on Rumi's poetry, Rumi, 1997, p. 47).

The above quotations provide some indication of the concerns and direction of this article: the phenomenon of human vulnerability as an existential given. This phenomenon can be metaphorised as 'wound' and announces both a great dilemma and a potential gift. The dilemma refers to that of Narcissus and his great flight from human vulnerability. The 'gift of wound' refers to what will be called 'soulful space', a freedom for vulnerability, in which the humanising potential of 'wound' connects us empathically with others. The meaning and sense of 'soulful space' can be clarified and evoked through encountering and dwelling with the issues raised by what has been called 'narcissism'. This article wishes to explore some of the implications of this encounter.

A compassion for vulnerability may be an important existential task in a world that still easily lurches towards fantasies, systems and technologies of hoped-for invulnerability and purity, with its vision of a great transcendent winner; a vision of power rather than inclusive empathy.

'Narcissism' as a technical term within psychoanalysis and the field of psychopathology is surrounded by much theorising and jargon. Yet, in spite of this, the discourse refers to

The Indo-Pacific Journal of Phenomenology (IPJP) can be found at www.ipip.org.

The IPJP is a joint project of Rhodes University in South Africa and Edith Cowan University in Australia. This document is subject to copyright and may not be reproduced in whole or in part via any medium (print, electronic or otherwise) without the express permission of the publishers. 
patterns of experience and behaviour that are instructive when considering some of the central existential dilemmas of being human. It may be an unfortunate term as it has been used like much of psychiatric terminology to diagnose and judge the behaviour and experiences of others in a way that negatively values a certain kind of selfabsorption. It has been elaborated to characterise a whole style of being-in-the-world that tries to defend against the vulnerability of feeling needy and incomplete. As such, there has been much theorising about the defensive styles that are adopted (see, for example, Mollon, 1993), and in its extreme forms, a diagnostic category called 'Narcissistic Personality Disorder' has been constructed. Yet, the discourse surrounding this phenomenon points to a complexity of experiencing that is best spoken of in terms of metaphor and poetic narrative, and here is where the dry logic of psychoanalytic theory becomes more alive and where one may resonate with some of the existential dilemmas revealed beyond this specialist discourse. The existential themes centre on a 'wound of longing', how we bear this wound, and even find it as a gate and passage to some of our deepest existential possibilities. This dimension touches our human concerns to a degree that has been called 'spiritual' or 'ontological', and this discourse may speak further about how a certain kind of opening to the 'wound of longing' can invite us towards home-comings of great participation and belonging.

The aims of this article are two-fold:

Firstly, to indicate how the myth of narcissus and the way it has been taken up by the psychoanalytic tradition can be expressed in more phenomenological and 'experience-near' ways. In this pursuit, guidance has been taken from Gendlin's experiential phenomenology (1973) and his distinction between the logical and responsive orders (1997). This article thus adopts a style that attempts to be both evocative and logical in the way that it proceeds in order to present the potential 'aliveness' of the emerging phenomenon (Todres, 1998, 1999b, 2000a, 2004).

Secondly, to evoke and articulate the phenomenon of 'soulful space' as an authentic response to narcissism. The word 'soulful' is not used in a primarily religious sense, but rather as an adjective that has gained currency in western culture as reflected in dictionaries such as the Concise Oxford Dictionary and Collins Shorter Dictionary and Thesaurus indicating 'full of sentiment or emotion', 'evoking deep feeling' and 'not mechanical or heartless' (Allen, 1990; Makins, 1995). If, as will be shown, narcissism centrally involves a flight from vulnerability in order to attain a kind of 'freedom from wound', 'soulful space' refers to a different kind of freedom or 'spaciousness' that can tolerate or embody the vulnerability of 'soulfulness', a 'freedom for wound'. The article concludes with a description of 'soulful space' that combines both freedom and vulnerability as an existential possibility. Rather than being summative, the final stage of this article will prioritise an evocative style which invites an embodied 'holding' of the ambiguous 'felt sense' of 'soulful space' as 'freedom-wound'.

\section{The drama and myth of Narcissus}

Essentially, the Greek myth of Narcissus unfolds a drama in which Narcissus, a beautiful young man, becomes fixated and fascinated by an illusion; that his image in a pool of water can be grasped and possessed. He becomes enamoured with this surface image of himself to the exclusion of all other possible relationships. The core quest is to be at one with the beautiful picture. This fascination binds his energy and attention, and the drama unfolds through a number of stages as the futility and desperation of his quest to possess his image becomes apparent. In one version of the myth, Narcissus finally kills himself in a mood of despair and isolation.

The Indo-Pacific Journal of Phenomenology (IPJP) can be found at www.ipip.org.

The IPJP is a joint project of Rhodes University in South Africa and Edith Cowan University in Australia. This document is subject to copyright and may not be reproduced in whole or in part via any medium (print, electronic or otherwise) without the express permission of the publishers. 
This tragic story has been interpreted in a number of ways. One way that psychologically-minded people have interpreted it is as a metaphor for how we can become alienated from the nourishment of our lived experience by turning ourselves into an image or object. This surface image of ourselves is always elusive and precarious, yet Narcissus is desperately enthralled by the hope of grasping and attaining this 'great love'. There is the sad image of him leaning over the pool and extending his grasping hand towards his image under the water, only to find that the image ripples away and evades him, leaving his desperate longing insatiate. He lives with this insatiability and, as the story unfolds, tries to find compensations and various strategies that will either soothe his pain or keep his hope alive.

The tragedy of this drama is about how such fire of longing progressively drowns in the mood of isolation. Ovid, the Roman writer who chronicled this drama, evokes the scene and mood of isolation as follows:

'There was a clear pool with shining silvery waters, where shepherds had never made their way; no goats that pasture on the mountains, no cattle had ever come there. Its peace was undisturbed by bird or beast or falling branches' (Ovid, (43 BC-17 or 18 AD) 1955, p. 85).

So what we have in the myth of Narcissus is someone who has great beauty and potential, and who is not being carried forward into the richness and possibilities of relational life. There is the shocking deprivation in which his longing is mocked. And it is the mocking of his longing that has been contemplated by the psychoanalytic tradition in interesting ways.

\section{Self and other}

Freud and others have written about the naturalness of what they call 'primary narcissism' (see, for example, Morrison, 1986). According to this view, babies are naturally inclined to respond to confirmation that their desires and longings can be fulfilled. They are passively or actively demanding of such responsiveness in what Freud saw as a self pre-occupied with itself. When they are nourished in this way, both physically and emotionally, they receive confirmation that their feelings and desires are welcome. The field of 'me' becomes a productive source of information and direction, and forms the basis of a degree of inner freedom and vitality. This has been called 'healthy narcissism'.

But both 'primary narcissism' and 'healthy narcissism' may be unfortunate terms in that the actual experience may not be one of exclusive self-absorption as indicated in the myth, but rather unproblematic relationality and responsiveness at that level. Both Freud and Klein (Livingstone Smith, 1995) have been noted to have a conflict model of relational life. This view assumes that to be so-called 'self-involved' in pleasure is different from the action of being in relation with another. Both Kohut and Winnicot appeared to understand this and articulated a view of early self-other relationships in which self-reference is not the opposite of relating to others. For Kohut (1971), self-feeling is not antithetical to relationality. Winnicot (1965) makes this kind of complementarity even more explicit. He speaks of how babies come to enjoy the space of their own play. Such 'own-ness' is not narcissistic self-exclusiveness but an interpenetrating field of self and other - never only self and never only other. So, for Winnicot, and some intersubjective theorists (Stolorow, et al., 1987), narcissistic isolation, as in the myth of Narcissus, is never primary and exclusive but rather only occurs as a contraction of the more original interpenetrating play of going-on-being, in which self and other play hide and seek.

When there has been sufficient welcome and interaction of this kind, a person develops a

The Indo-Pacific Journal of Phenomenology (IPJP) can be found at www.ipip.org.

The IPJP is a joint project of Rhodes University in South Africa and Edith Cowan University in Australia. This document is subject to copyright and may not be reproduced in whole or in part via any medium (print, electronic or otherwise) without the express permission of the publishers. 
certain strength, which the psychoanalysts have problematically called 'ego-strength'.

'He knows not only what he does not want but also what he wants and is able to express this irrespective of whether he will be loved or hated for it' (Miller, 1987, p. 50).

But if psychoanalytic thinkers have written extensively on the 'ways the longing is mocked' by self and others, how may we describe this 'longing', its feeling and landscape?

\section{The wound of longing}

Before it turns into a sense of shame and deficiency, there is simply a vulnerability given with the human condition. Let us approach this slowly before we describe it more fully. In opening towards it, it may come like the song: 'sometimes I feel like a motherless child, sometimes I feel like a motherless child, sometimes I feel like a motherless child, far, far from my home'. So one aspect of opening towards all this is a sense of disconnection from a source of nourishment and continuity: a tear in the sense of simple going-on-being. There is a felt vulnerability of need and incompleteness, of wanting; a sense of something missing, and a stretching towards what may come. The energy of Eros is always leaning towards the life that is not yet, and in the experiencing of the multiple circumstances of living, we are accompanied by this vulnerability that knows the softness of flesh and the relief of welcoming the one who returns. One may also move towards what this is in the salt of tears, of loss. One existential writer expresses an aspect of this vulnerability as follows: 'To be human means to be torn' (Kastrinidis, 1988, p. 179). There are different paths towards this opening: the throb of sex, the pain of an aching back, hunger that would swallow the world.

So, in opening to the sense of vulnerability in these ways, what is revealed is this human realm of what we go through. Leonard Cohen expresses this well in his song Here it is: 'Here is your sickness, your bed and your pan; and here is your love for the woman, the man' (Cohen, 2001). What may come with this sense of vulnerability is a longing, as if our body knew its heart's desire. And how can we interpret the heart's desire? The psychoanalytic tradition has literalised this to an actual event: oneness with mother. To quote one psychoanalytic thinker '...they are trying to re-experience the missing connectedness of their primary attachment' (Livingstone Smith, 1995, p. 124). This tradition would see the loss ... as an event of personal history in which oneness with mother constitutes the original wholeness (Todres, 1993). However, the feeling of connectedness for which we long may not be essentially back there in time as an event or person (even though this may be one occasion for longing). Rather, the feeling of connectedness that the body seems to know may be implicitly right here-and-now in the flow of relational life. So, in opening to the wound of longing and vulnerability, one may stand open and trusting to what may come and what may be longed for. But equally one may not. One may come to hate a state of vulnerable longing and embark on a journey of great refusal. Some implications of this refusal to admit vulnerability and longing will now be explored.

\section{Some forms of refusal to the wound of longing and the realm of vulnerability}

When admitting vulnerability and longing, 'self' may be open, flowing and dynamic; vulnerable to a range of relational, embodied, full-feeling; not freezing self into an object or falling into partial grasping of a self-image. There is less a sense of repetition and more novelty and less preoccupation with the boundary that says: 'I am this only.'

But we can be shocked, and are shocked, into refusing vulnerability and the flow of longing and what comes, by an action of self-contraction. We are shocked into a self-contraction in different ways and may not easily get back into

The Indo-Pacific Journal of Phenomenology (IPJP) can be found at www.ipip.org.

The IPJP is a joint project of Rhodes University in South Africa and Edith Cowan University in Australia. This document is subject to copyright and may not be reproduced in whole or in part via any medium (print, electronic or otherwise) without the express permission of the publishers. 
the flow of intimate relational life - here we may remember the drama of Narcissus. Psychoanalytic writers have articulated these reactions in different ways but, in their meditations on the narcissistic ways of flight from vulnerability, emphasise the doomed attempts to puff up and maintain forms of selfsufficiency that strain against admitting otherness. It may be helpful to indicate briefly some of these ways and their implications in relation to the question: how does one refuse vulnerability and longing?

\section{Hating the self that is vulnerable or longing}

Before one defends strongly against vulnerability and longing, one may simply hate these feelings or the self that has them, and experience great shame.

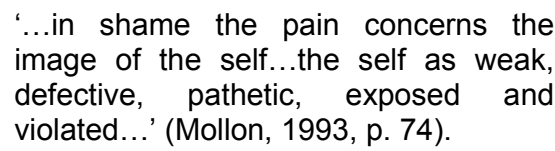

There is a shock of painful self-consciousness in which one looks at oneself as a problem to be solved, an object to be changed. One may become very attuned to what others expect and may experience an embarrassed selfconsciousness when one violates this expectation. In shame, one has been captured by the other and experiences great self-doubt in the other's gaze. In its extreme forms, it is as if the other is saying 'you are nothing without my approval or admiration', and, in the extreme forms of selfdoubt, it is as if one is saying to oneself ' $\mathrm{I}$ am nothing without what I should be'. In this shock of self-objectification, of viewing oneself from an outside perspective, one may become preoccupied with one's body as sick, as breaking up, of its shape needing to be altered; there is a painful standing out.

\section{The strategy of self-sufficiency: 'I don't need'} Then there may be the path of refusing vulnerability by trying to pretend that one does not need others or otherness; addiction to the feeling of self-sufficiency. For, Narcissus, in a sense, there is no other and he tries to feed himself with himself. In this trajectory we can try to puff ourselves up with images of our own specialness or strength. The jargon for this dimension has been referred to as 'grandiosity'. The construction of a more perfect ideal self is attempted; one that one is in control of, and that can armour oneself against, personal vulnerability. When this feels relatively successful, one may feel somewhat elated, but in a rather precarious way. Exposure to the limits that come with the acknowledgement of personal vulnerability are rejected in different ways: aging, death, the uncontrollable contingencies that come with this human realm. Others may detect a note of aloofness, arrogance or scorn in one's voice at these times as if the tone says 'I don't need you and am more or better than others'. A victorious mood of self-sufficiency in being in love with one's own mirror image may leave the other feeling redundant. There may be a lot of energy expended on these images of specialness, strength or goodness in different ways.

However, to be less than this specialness or strength is to become 'only ordinary' and to fail. The self-esteem based on the ideal image crashes, and a feeling of great depression may ensue in what feels like the 'dreaded truth' of one's deficiency in the face of one's failed ideal selfimage. One variation of the precariousness of keeping an ideal self-image going is that it may flicker like an unstable movie projector, and the unstable sense of self-esteem may fluctuate between feelings of expansive ideal identity, achievement, and feelings of deficiency and ideal identity failure.

\section{The strategy of seeking others as mirrors of an ideal self}

Another aspect of Narcissus' strategy was to use others as a mirror of the ideal self he was trying to attain and forever possess.

The Indo-Pacific Journal of Phenomenology (IPJP) can be found at www.ipip.org.

The IPJP is a joint project of Rhodes University in South Africa and Edith Cowan University in Australia. This document is subject to copyright and may not be reproduced in whole or in part via any medium (print, electronic or otherwise) without the express permission of the publishers. 
'Narcissistic individuals demand that the world provide them with unqualified, unremitting reassurance of their beinga-whole' (Kastrinidis, 1988, p. 169).

One may go into a rage when this is not forthcoming. Or one may feel deeply insulted when others do not help one to feed oneself with one's own desired image. Ironically, one's need for others is very great in this quest, as the possibility of success in self-sufficiency needs a great deal of support. One becomes exceedingly sensitive to others' views of oneself as so much is at stake. Words can bring one down and it can feel like one is fighting for one's soul. One may be afraid at the power that others have in this mirroring need. This can constitute a deep ambivalence about others' power: great desire for being defined by others yet great fear about being possessed in such a way. In such forms of interpersonal sensitivity and extremity, a lot of energy is expended on finding a mirror that admires the hoped-for ideal self-image. The need to see oneself in such a mirror can carry the level of panic and desperation associated with a life or death issue. When others do not provide this for us, we may experience the kind of insult that 'cuts us to the quick, that assails us where we live, that threatens our identity or our self-image, or our ego-ideal or our self-esteem' (Levin, 1993, p. xiv). We take offence as the image of our ideal self is injured. Or we may become addicted to admiration and do what it takes to keep another mesmerised, whether through masochistic seductions or sadistic control. We may attempt to achieve a painless oneness with a sense of nourishment or power that we control through drugs, alcohol, magic or fame. In this regard, Kastrinidis (1988) notes how an authentic fusion with oneness with another is different from this as it 'always leaves open the possibility of pain...' (p. 178).

At certain phases on this path, there is a sense of deficient emptiness as no true nourishment seems to happen; one is trying to live with the kind of nourishment that is 'ghostly' and not very substantial. If one becomes addicted to admiration and puts oneself 'on show', at the core, one does not feel loved for the person one is; there is always a suspicion at the centre of this kind of feeling admired. This is the life of compensation. We would 'exchange a walk-on part in the war for a lead role in a cage' (Gilmour \& Waters, 1975). Something feels missing and can result in a strategy of self-sabotage that mocks one's own success in this regard as if to taunt: 'admiration is a pale substitute for true welcome and love'. Here, one may even cynically resign oneself to the absence of feeling respected or understood. One may be left in a chronic state of envy that, somehow, a place in the sun is only possible for others; an endless world of comparing 'haves' and 'have-nots'. One may feel scornful of others' feelings because one cannot take one's own feelings seriously. At its extreme, such pain of envy may fuel a desire to destroy what others have got or to destroy what one can't possess rather than have the desired object or person belonging to someone else. This is a sad, predatory state of affairs, of stalking empty corridors, pale in the shadows.

\section{The strategy of merging with a great or special 'other'}

A further interpersonal variation of seeking a fixed, strong, ideal and special self is by identifying or merging with another who seems fixed, strong, ideal and special: 'you are great and I am part of you'. One enters into the relief of an 'I' that is 'we' and who always wins the cup. We would defend to the death this 'we', this great hope for oneness without vulnerability. To be someone's twin, give me similar clothes; to be a fan, to find a hero, to join a cult, we would pay the price gladly. And at the end of the war we were just following orders.

In all these ways, psychoanalytic writers have indicated a flight from vulnerability and longing. They have done this in theoretically dense ways but there are rich insights when read metaphorically and with a light touch. Their

The Indo-Pacific Journal of Phenomenology (IPJP) can be found at www.ipip.org.

The IPJP is a joint project of Rhodes University in South Africa and Edith Cowan University in Australia. This document is subject to copyright and may not be reproduced in whole or in part via any medium (print, electronic or otherwise) without the express permission of the publishers. 
insights, particularly with regard to psychotherapeutic and spiritual directions, can be fruitfully enhanced, and I would like to move on to a vision of possibilities inspired by A. H. Almaas and Eugene Gendlin. Both of these writers are helpful in moving towards an understanding of 'soulful space: Almaas, by considering the kind of 'spacious freedom' that characterises the essential openness of human identity; and Gendlin by inspiring a vision of 'soulfulness' that is embodied, deeply felt and open.

\section{An essentialist approach: A. H. Almaas}

In his writings on narcissism, Almaas draws extensively on the psychoanalytic tradition but reframes these insights to characterise 'everyday' narcissism as a universal dilemma and as being relevant to spiritual practice. In his view, what has been referred to as Narcissistic Personality Disorder is 'basically a severe form of the narcissism of everyday life' (Almaas, 1996, p. 27).

Almaas sees the central problem of narcissism as the act of self-objectification, the attempt to flee from the rich and textured seamlessness of immediate experience by using the filter of thought and self-definition. He thus sees such self-objectification as almost inevitable. In such acts of self-objectification, we identify and define ourselves only partially. What this means for Almaas is that we fail to live our multidimensional capacities and true patterns. Moreover, he has a definite view about what these true patterns essentially are, such as value, strength, intelligence, will, nourishment, peace and a number of other positive essential qualities that come with what he calls the 'essential self'. He has a tantric view of the narcissistic strategies in which our radiant potentials are hiding. Thus, poor self-esteem hides an essence of intrinsic worth and value; arrogance can transform into an essence of the humble openness of "not knowing'; a sense of grandiosity can transform into the essence of a sense of personal uniqueness and destiny; the need for mirroring can transform into an essence of the capacity to perceptually 'drink in' the world free from the need for selfaffirmation; a feeling of betrayal and rage can transform into a determination not to betray one's own process; the intolerance of insult to selfesteem can transform into a capacity to forgive life its changes and a differentiated ability to look after oneself; shame and the dilemma of oneselfas-object can transform into the essence of peacefulness about the flow of how one appears; the search for invulnerability can transform into the deeper essence of one's indestructible true nature; the painfulness of the wound of longing can transform into the essence of compassion, one that connects rather than separates.

For Almaas, all this is possible if one clears the way for 'essential self'. It should be noted that he is not speaking here about the extremes of Narcissistic Personality Disorder, but of a path of spiritual development beyond 'everyday' narcissism. His deepest solution to the act of self-objectification is to move towards disidentifying with all the ways we define ourselves and are defined by others. To not identify means not to objectify, and he recommends forms of self-inquiry that gradually face all these forms of self-objectification until the multiple 'diamond' facets of 'essential self' can be restored and shine through in their myriad radiant forms.

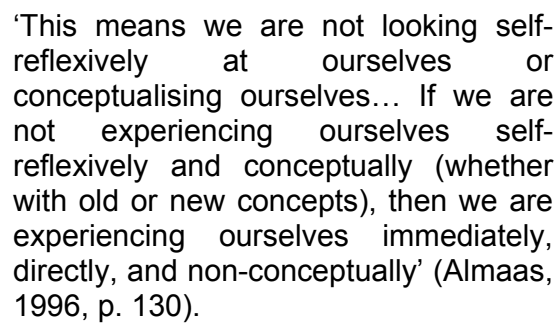

At certain stages in the radical deconstruction of structured identity, there is a sense of free presence that sees through the substantiality of these forms of self-identity. There may be a sense of great space and freedom. This wonderful

The Indo-Pacific Journal of Phenomenology (IPJP) can be found at www.ipip.org.

The IPJP is a joint project of Rhodes University in South Africa and Edith Cowan University in Australia. This document is subject to copyright and may not be reproduced in whole or in part via any medium (print, electronic or otherwise) without the express permission of the publishers. 
mysticism can touch a sense of timelessness and completeness: Boddhidharma's 'vast space, nothing holy'. However, this is not the same as the more complex phenomenon that I wish to call soulful space. It is possible to become too enamoured with 'free presence' and the resolution of human vulnerability into vastness. Such spaciousness can become dissociative if it is not integrated with the historical specificities of 'me meeting you' in all life's specific occasions (Todres, 1999a, 2000b). It is to this that I wish to return a little later.

For now, I would just like to express a degree of caution about Almaas's essentialism. One's 'true pattern' may not be essentially 'there' as essential contents existing in themselves such as 'love, peace, strength, value'. Rather, these contents may be better understood as derivatives of a process that occurs in life; a life of interaction in which phenomena are co-created as one meets the specifics of life and situations. Emphasising and honouring such specifics grants forms of experience that exceed any ways of categorising them and give much more nuanced qualities, emotionally rich with aspects, that, who knows, exceed any conceivable essence no matter how skilfully articulated. Such novelty is 'wet through' with the events of time and meetings that have never before quite happened like this. And here we come to Gendlin.

\section{An existential approach: Eugene Gendlin}

In a paper explicitly on narcissism, Gendlin has criticised the way that the cultural discourse on narcissism has developed.

\begin{abstract}
"What is called "narcissism" (anything other than the imposed order) is much more and different than the term implies' (Gendlin, 1987, p. 12).
\end{abstract}

He notes a number of distinctions that need to be made and that haven't been made and how this has led to a conflation of two different kinds of self-activity: one, the process of self-focused attention in which complexity and richness emerge and two, the structure-bound process of defining self, other and world, in which there is a freezing of such process (see also Gendlin, 1964).

In what Gendlin calls the 'life forward' direction, there is an acknowledgement of the 'unfinishedness' of human identity and desire, and how the body knows a sense of what is needed and what the next step could be. This is an existential approach in that there are no final, unconscious contents to be realised; the content of experiencing is always more than, and richer than, any way of summarising a particular unconscious potential or content. The body knows a sense of wholeness that is open rather than frozen. It is not a totalised or final wholeness unable to admit the novelty and specificity of new happenings. We are always potentially invited into a greater whole that is open and fertile. Such a coming to wholeness enjoys the sigh of recognition, but the openness of this wholeness welcomes the longing of what still may come. Such being 'in process' is expressed in a similar spirit by a psychotherapist in the Heideggerian tradition: there is '...a readiness to receive whatever it is that wants to show itself, to serve as an opening for the gathering of Being through a calm, selfcomposed waiting upon or attentiveness to Being' (Kastrinidis, 1988, p. 180). So, the body knows intimately the taste of unfinishedness, and even more, of separation, being-torn and longing. And the body recognises the taste of wholeness, of being at one, of being continuous with something much greater; a moving whole that is already adventuring. The body knows that it can be let into a sense of relatedness and process, invited into the flow of carried forward wholes.

To grasp wholeness as a content, a summary, a finished meaning, is to freeze the openness and rhythm of going-on-being and to fall into objectification. In our '...pre-occupation with any single possibility (ideal or even wholeness),

The Indo-Pacific Journal of Phenomenology (IPJP) can be found at www.ipip.org.

The IPJP is a joint project of Rhodes University in South Africa and Edith Cowan University in Australia. This document is subject to copyright and may not be reproduced in whole or in part via any medium (print, electronic or otherwise) without the express permission of the publishers. 
[we] lose [our] freedom to take up [our] full inheritance as a diverse, ever evolving presence in the world' (Kastrinidis, 1988, p. 174). In such pre-occupation and grasping for a fixed ideal self, we would lack the freedom of being-incomplete, the nourishing brightness of what can come in such un-knowing. The body affirms the value of hungry longing and quivering vulnerability as the human space of welcome.

The dilemma of Narcissus is not that being-inprocess has become unavailable to him but that he does not like such a process and tries to solidify it as a hoped for achievement of invulnerability and self-sufficiency. Here we return to some of the strategies that I have indicated.

So, we have been coming to what I wish to call 'soulful space' in hints and turns, and I would like to take this a bit further.

The creation of 'soulful space': mountains and valleys holding one another

At its core, the human heart of Narcissus is simply the vulnerability that is given with the human realm, between earth and sky. But then, there is a panicked flight from this into a hopedfor freedom: the 'freedom from otherness', in which one is self-sufficient and complete.

The notion of 'soulful space' wishes to indicate a different kind of freedom - a 'spaciousness' in which vulnerability is not avoided, but rather, embraced. Soulful space is the mixing of vulnerability and the kind of freedom that embodies a willingness to 'wear' and 'move' within the vulnerabilities of this human realm. Both Almaas and Gendlin indicate the kind of 'flow' of 'being-with' that can embrace human vulnerability, need and 'unfinishedness.'

Soulful space may also be metaphorised as freedom-wound, the kind of human openness that is always touched: a different kind of freedom from the freedom that is 'above it all'.
Soulfulness embodies the 'valleys' of many heartfelt historical moments. It includes the many things that we are touched by in opening to 'otherness' and the seasons of time. Soulfulness is history and the marks of being historical beings.

As one goes through this 'manyness', there may be a growing sense of the taste of this inclusiveness, this mixing, this holding space, this stretching of the seasons of time. There may be a growing taste of the fertility of flow, and the taste of the freedom of a space that can hold and move with the 'manynesses', its specific vulnerabilities. And this mixing always carries more than just the feeling of spaciousness that just 'lets go'. Rather, it is a spaciousness that also 'lets in'. For within the intimate touching of what one has gone through, there is a treasure coming from such 'salt' that is more complex than the peace of space and the freedom of flow.

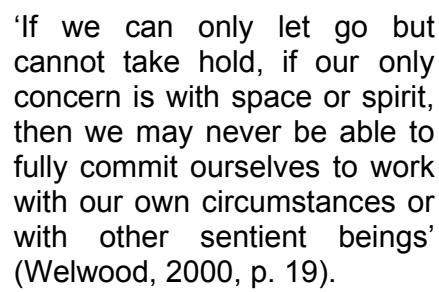

In this taste there is also the acknowledgement that living forward means separations and bindings, so there is also pain - a beautiful pain in living forward, and in giving up what we have embodied. This beautiful wound is the human realm. It is the realm that Narcissus would reject. It is not the kind of pain that withdraws into isolation. Rather, it is the more mellow wound of longing that is worn gladly as we look deeply at one another and care for one another as fellow carriers. The wound sings the song of separation and longing, and the body (whatever that is altogether) remembers both connection and separation; a soulful space where we can deeply meet. And does this mellow wound disappear?

The Indo-Pacific Journal of Phenomenology (IPJP) can be found at www.ipip.org.

The IPJP is a joint project of Rhodes University in South Africa and Edith Cowan University in Australia. This document is subject to copyright and may not be reproduced in whole or in part via any medium (print, electronic or otherwise) without the express permission of the publishers. 
If it did, great love would disappear. Could it be an important source of human compassion?

\section{Finale}

Carl Jung is standing on this road when, towards the end of his life, he wrote:

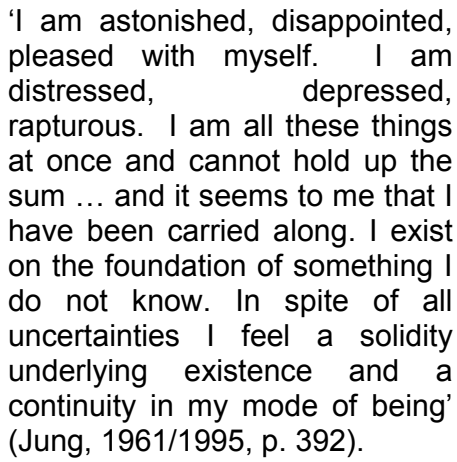

The treasure of the wound of longing is the taste of the beauty and poignancy of human participation; the essence of relationship, the 'wefeeling' in mutual vulnerability. Soulful space: to be a place where this can happen - not just 'soulful', merged in the cry; not just 'space', the presence of flow and impartiality. This 'we feeling' in mutual vulnerability may finally be the place that grounds more humanised forms of institutions and cultures, an existential achievement that would remember and take heed of Narcissus in his different forms.

\begin{abstract}
About the Author
Les Todres, $\mathrm{PhD}$, is a clinical psychologist and Professor of Qualitative Research and Psychotherapy at the Institute of Health and Community Studies, Bournemouth University (England). His previous occupational roles have included head of a student counselling service and director of a clinical psychology training programme. He has also worked within NHS clinics and GP practices. He has published in the areas of Phenomenological Psychology and Integrative Psychotherapy. In his current position, he co-founded and co-leads the Centre for Qualitative Research. He also provides clinical supervision to psychological therapists at the Intensive Psychological Therapies Service in Poole.
\end{abstract}

\section{References}

Allen, R. E. (Ed.) (1990). The Concise Oxford Dictionary of Current English (8th ed.). Oxford: Clarendon Press.

Almaas, A. H. (1996). The Point of Existence: Transformations of Narcissism in Self-realization. Berkeley, California: Diamond Books.

Cohen, L. (1992). Anthem. The Future. Columbia, Sony Music: New York.

Cohen, L. (2001). Here it is. Ten New Songs. Columbia, Sony Music: New York.

Gendlin, E. T. (1964). A theory of personality change. In P. Worchel \& D. Byrne (Eds.), Personality Change. New York: John Wiley \& Sons (pp. 100-148).

Gendlin, E. T. (1973). Experiential phenomenology. In M. Natanson (Ed.), Phenomenology and the Social Sciences, Vol.1. Evanston: Northwestern University Press (pp. 281-319).

Gendlin, E. T. (1987). A philosophical critique of the concept of narcissism: The significance of the awareness movement. In D. M. Levin (Ed.), Pathologies of the Modern Self: Postmodern Studies on Narcissism, Schizophrenia and Depression. New York: New York University Press (pp. 257-304).

The Indo-Pacific Journal of Phenomenology (IPJP) can be found at www.ipip.org.

The IPJP is a joint project of Rhodes University in South Africa and Edith Cowan University in Australia. This document is subject to copyright and may not be reproduced in whole or in part via any medium (print, electronic or otherwise) without the express permission of the publishers. 
Gendlin, E. T. (1997). How philosophy cannot appeal to experience, and how it can. In D. M. Levin (Ed.), Language beyond Postmodernism: Saying and Thinking in Gendlin's Philosophy. Evanston, Ill: Northwestern University Press (pp. 3-41).

Gilmour, D. \& Waters, R. (1975). Wish you were here. Wish You were Here. Harvest, EMI: USA.

Jung, C. J. (1961/1995). Memories, Dreams and Reflections. Recorded and edited by Aniela Jaffé. Translated from German by Richard \& Clara Winston. London: Fontana Press.

Kastrinidis, P. (1988). The phenomenology of narcissistic neurosis. Humanistic Psychologist. 16, 168-185.

Kohut, H. (1971). The Analysis of the Self. New York: International University Press.

Levin, J. D. (1993). Strings and Arrows: Narcissistic Injury and its Treatment. New York: Jason Aronson.

Livingstone Smith, D. (1995). A brief history of narcissism. In J. Cooper \& N. Maxwell (Eds.), Narcissistic Wounds: Clinical Perspectives. London: Whurr (pp. 3-15).

Makins, M. (managing editor) (1995). Collins Shorter Dictionary and Thesaurus. New York: Harper Collins.

Miller, A. (1987). Drama of Being a Child (translated by Ruth Ward). London: Virago Press.

Mollon, P. (1993). The Fragile Self: The Structure of Narcissistic Disturbance. London: Whurr.

Morrison, A. P. (Ed.) (1986). Essential Papers on Narcissism. New York: New York University Press.

Ovid, 43 BC-17 or 18 AD (1955). The Mmetamorphoses of Ovid. Harmondsworth: Penguin.

Rumi, J. (1997). The Essential Rumi (translated by Coleman Barks with John Moyne). Edison, N.J.: Castle Books.

Stolorow, R. D., Brandschaft, B \& Atwood, G. E. (Eds.) (1987). Psychoanalytic Treatment: An Intersubjective Approach. Hillside, N.J.: Analytic Press.

Todres, L. (1993). Psychological and spiritual freedoms: Reflections inspired by Heidegger. Human Studies $16,255-266$.

Todres, L. (1998). The qualitative description of human experience: The aesthetic dimension. Qualitative Health Research, 8, 121-127.

Todres, L. (1999a). How does liberating self-insight become tacit understanding? A phenomenological enquiry. In G. Watson, S. Batchelor \& G. Claxton (Eds.), The Psychology of Awakening. London: Rider (pp. 177-186).

Todres, L. (1999b). The bodily complexity of truth-telling in qualitative research: Some implications of Gendlin's philosophy. Humanistic Psychologist, 23, 283-300.

The Indo-Pacific Journal of Phenomenology (IPJP) can be found at www.ipip.org.

The IPJP is a joint project of Rhodes University in South Africa and Edith Cowan University in Australia. This document is subject to copyright and may not be reproduced in whole or in part via any medium (print, electronic or otherwise) without the express permission of the publishers. 
Todres, L. (2000a). Writing phenomenological-psychological descriptions: An illustration attempting to balance texture and structure. Auto/Biography, 3, 41-48.

Todres, L. (2000b). Embracing ambiguity: Transpersonal development and the phenomenological tradition. Religion and Health, 39, 227-237.

Todres, L. (2004). The meaning of understanding and the open body: Some implications for qualitative research. Existential Analysis, 15, 38-54.

Welwood, J. (2000). Toward a Psychology of Awakening. Boston \& London: Shambhala.

Winnicot, D. W. (1965). The Maturational Process and the Facilitating Environment. New York: International University Press.

The Indo-Pacific Journal of Phenomenology (IPJP) can be found at www.ipip.org.

The IPJP is a joint project of Rhodes University in South Africa and Edith Cowan University in Australia. This document is subject to copyright and may not be reproduced in whole or in part via any medium (print, electronic or otherwise) without the express permission of the publishers. 